poun ds, at 60 miles per hour. Engine runs have been increased from 140 to 400 miles, crews being changed at intervals. As a result there are fewer locomotives in use to-day than ten years ago. Goods waggons have increased in size and decreased in number, and ordinary passenger coaches have been replaced by Pullman cars. The ton miles for goods have risen from 410 to $447 \times 10^{9}$, but the passenger miles have fallen from 47 to $31 \times 10^{9}$. Revenue increased from $6 \cdot 2$ to $6.3 \times 10^{9}$ and operating expenses decreased from $5 \cdot 8$ to $4.5 \times 10^{9}$ dollars. Mr. Dickerson is not satisfied that 45 per cent of the locomotives in use are more than twenty years of age He shows that it is in the end more economical to replace old locomotives rather than to rebuild them. He considers that the diesel-electric locomotive has a wide field of usefulness.

\section{Smoke Abatement}

ThE Quarterly Journal of the National Smoke Abatement Society, issued by the Society, 23 King Street, Manchester, among other things analyses the progress of smoke abatement as revealed by the latest Report on Atmospheric Pollution issued by the Department of Scientific and Industrial Research. This records for the average of a number of stations a decrease in 'total deposits', in tar, and sulphate averaging 16 per cent, 24 per cent, and 19 per cent respectively. While this decrease may partly be due to industrial depression, it is concluded that there has been a definite reduction of domestic smoke. Some of the figures, if correct, suggest that current ideas require revision. While the atmosphere of industrial cities seems to be improving, conditions in London get worse, and now appear to be similar to those of Hunslet-an industrial area in Leeds. Again, the suburbs of Leeds yield figures better than those of Southport. Such comparisons will suggest the need for caution in interpretation, but the figures show that conditions can be improved, and the Journal does a good service in emphasising this.

\section{Food Technology}

REFERENCE has previously been made in these columns to the problems of food preservation and their importance to modern civilisation. The more scientific aspects of the subject are dealt with in the reports of the Food Investigation Board and the Empire Marketing Board, and references to the extensive literature on the subject can be found in the "Index to the Literature of Food Investigation". Food Technology is described as a monthly review of manufacture, packing, and transport for production managers, food chemists, and engineers, and is designed to make known the work of research centres and to secure greater publicity for their achievements. The journal contains articles on different aspects of the food trade, answers to readers' inquiries, and notes on recent patents, amongst other features. It appears that it should fulfil its object of keeping those engaged in modern food factories in touch with research work on the treatment of food, as well as with the necessary auxiliary trades. It is edited by Dr. H. D. Law, 153 Stratford High Street, London, E.15; price $12 s$. a year.

No. 3276 , VoL. 130$]$

\section{Best Books in 1930}

UNDER the title "Best Books of 1930 " a selected list of books published during that year has recently been issued by Mr. Alex. J. Philip, "Lodgewood", Gravesend, and Messrs. Simpkin Marshall, Ltd., London, E.C.4. The list is classified on the Dewey Decimal System and has been selected with the help of many authorities, institutions, and societies. The main headings of the classification include general, philosophy, metaphysics, religion, sociology, philology, science, arts, literature, and history, and these are subdivided into their various groups. About 2500 "Best Books" are thus classified for the year 1930 . Such a list should prove useful as a work of reference, and should be an asset to all lending and reference libraries, as well as to departmental and institutional libraries. Nevertheless, we venture to suggest that since the comparative value of a book is often a matter of opinion, such a selected list cannot be expected to be anything other than a tentative guide to choice.

\section{Announcements}

THE Third International Congress of Cytology will be held in Cambridge at the end of August 1933. Further particulars will be published in due course.

Mr. I. W. M. Armstrong-Black has been appointed assistant agricultural chemist, Nyasaland (Colonial Agricultural Service).

A sHort training course for curators and assistants has been arranged by the Museums Association to be held at Manchester on Sept. 27-30. The course will be devoted to the study of the technique and administration of science and art museums and galleries, and will include visits to the Manchester Museum at the University, the Manchester City Art Gallery and branches, the Whitworth Art Gallery, and the Royal Museum and Art Gallery, Salford. No fees will be charged for attendance. Applications for grants towards students' expenses in attending the course will be considered by the Committee and should be addressed to the Secretary, The Museums Association Short Training Course, Public Museum, Bootle.

ApPLICATIONs are invited for the following appointments, on or before the dates mentioned:- -An assistant agricultural chemist in the Department of Agriculture and Horticulture at the University of Bristol-Agricultural Advisory Office, 22 Berkeley Square, Bristol (Aug. 20). A lecturer in mechanical engineering at the Municipal Technical College, Hull -The Director of Education, Education Offices, Guildhall, Hull (Aug. 20). A principal of the Lester Technical School and Institute, Shanghai--The Secretary, Association of Principals of Technical Institutions, Chelsea Polytechnic, Manresa Road, S.W.3 (Sept. 1). An attendant for the Departments of Botany and Zoology at the North of Scotland

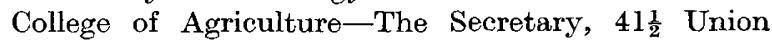
Street, Aberdeen. An assistant tobacco chemist in the Chemical Laboratories of the Ministry of Finance, Egypt--The Chief Inspecting Engineer, Egyptian Government, 41 Tothill Street, London, S.W.1. 